\title{
How Short-term Transdermal Treatment of Men with 7-oxo- dehydroepiandrosterone Influences Thyroid Function
}

\author{
R. HAMPL, J. ŠULCOVÁ, R. BÍLEK, M. HILL \\ Institute of Endocrinology, Prague, Czech Republic
}

Received January 31, 2005

Accepted March 29, 2005

On-line available April 26, 2005

\begin{abstract}
Summary
Dehydroepiandrosterone may influence thyroid function. Its metabolite, 7-oxo-dehydroepiandrosterone, a precursor of immunomodulatory 7-hydroxylated metabolites and thermogenic agent, belongs to candidates of steroid replacement therapy. The question was addressed whether its application does influence laboratory parameters of thyroid function. 7-Oxo-dehydroepiandrosterone in the form of emulgel, $25 \mathrm{mg} /$ day, was applied transdermally to 21 healthy men for 8 consecutive days. Morning blood was collected before the treatment (Day 0, Stage 1), during treatment (Day 5, Stage 2), on the first day after the last administration (Day 9, Stage 3), one week (Day 16, Stage 4), and 9 weeks (Day 72, Stage 5) after treatment termination. The levels of thyrotropin, free thyroxine and triiodothyronine, dehydroepiandrosterone, its sulfate and its 7-hydroxyepimers were measured. The changes were evaluated by analysis of variance and correlation analysis. During treatment a significant rise of $7 \beta$-hydroxy-dehydroepiandrosterone was observed, which persisted 1 week after treatment termination. No changes were observed in dehydroepiandrosterone and its sulfate. Though a slight but significant rise of TSH and of both thyroid hormones occurred during treatment, its levels soon returned to the basal values. It was concluded that treatment of 7-oxo- dehydroepiandrosterone affects the thyroid parameters only temporarily and that it provides a considerable persistent amount of $7 \beta$-hydroxydehydroepiandrosterone.
\end{abstract}

Key words

7-oxo-dehydroepiandrosterone $\bullet$ Transdermal application $\bullet$ Thyroid hormones

\section{Introduction}

Plasma levels of dehydroepiandrosterone (DHEA), its precursors and metabolites may be altered in thyroid disorders. Tagawa et al. (2000, 2001) demonstrated that in hypothyroid patients the levels of DHEA, its sulfate (DHEAS), pregnenolone sulfate, and both unconjugated and sulfated androstenediols were significantly lower than in age- and sex-matched healthy controls, while only the sulfated steroids were increased in hyperthyroidism. Altered DHEA levels were recently reported in men with hyperlipidemia, known as a risk factor in hypothyroidism (Šulcová et al. 2005).

It is also known that DHEA and some of its metabolites act as immunomodulators, in some instances counteracting the exaggerated effects of glucocorticoids on the immune system (Kalimi et al.1994, Kalimi and Regelson 2000). Recent reports from our and other 
laboratories have demonstrated that 7-oxygenated DHEA metabolites may be even more effective locally active immunoprotective agents than DHEA itself (for review see Morfin 2002).

In our recent paper (Hampl et al. 2003) we have pointed to a negative correlation between one of 7 hydroxylated DHEA metabolites, 7 $\beta$-hydroxydehydroepiandrosterone (7 $\beta$-OH-DHEA) and free triiodothyronine $\left(\mathrm{fT}_{3}\right)$ in euthyroid healthy subjects.

Both 7-hydroxylated DHEA metabolites are present in human blood in low nanomolar concentrations (Hampl et al. 2001) together with an intermediate of their interconversion, 7-oxo-dehydroepiandrosterone (7-oxoDHEA) (Marwah et al. 1999, Robinzon et al. 2001). When administerd to humans, 7-oxo-DHEA is metabolized to both 7-hydroxyepimers of DHEA, and as such may be one of several candidates of steroid replacement therapy (Hampl et al. 2000). In some countries (e.g. in the USA) it is available without prescription under the trademark 7-keto DHEA. Moreover, experimental evidence has been reported that this steroid is a potent thermogenic agent and it could reverse the effect of thyroid hormone removal on thermogenesis (Bobyleva et al. 1997). It was even suggested for prevention of Raynaud's attacks (abnormal digital vasoconstriction in response to cold) (Ihler and Chami-Stemman 2003).

With respect to the potential beneficial effects of 7-oxo-DHEA, we have been studying its various endocrine effects when given transdermally to male volunteers in the form of a well tolerated emulgel. One of the questions was whether, and if so how, does 7-oxoDHEA administration influence the thyroid laboratory parameters.

\section{Methods}

\section{Subjects}

The group of volunteers consisted of 21 informed male volunteers aged 20-70 years (44.8 114.4 , mean \pm S.D.). They were neither on regular medication nor had a health risk except for the higher age of some of them. The subjects were divided into small groups of 2-4 men each, who underwent treatment and blood collection together. The interval between treatments of successive groups was two weeks. The purpose of this arrangement was to avoid the seasonal effects as well as possible actual fluctuation of analytical methods. The whole study thus lasted 10 months.

\section{Treatment protocol}

7-oxo-DHEA was applied transdermally as an emulgel containing $0.5 \mathrm{~g}$ of 7-oxo-DHEA per $100 \mathrm{~g}$ (purchased from A. Nováček, Bochemie Inc., Bohumín, Czech Republic). The gel (5 g, corresponding to a daily dose of $25 \mathrm{mg}$ 7-oxo-DHEA) was applied onto an abdominal skin area before sleeping at 22:00 $\mathrm{h}$, for 8 consecutive days. Morning blood was collected after a night fast as follows: before the start of the treatment (Day 0, Stage 1), in the course of treatment (Day 5, Stage 2), on the first day after the last application (Day 9, Stage 3), one week- (Day 16, Stage 4), and 9 weeks (Day 72, Stage 5) after termination of the treatment, respectively. Blood sera were frozen and stored at $-20{ }^{\circ} \mathrm{C}$ till the analysis.

\section{Hormone analyses}

Serum $\mathrm{TSH}, \mathrm{fT}_{4}$, and $\mathrm{fT}_{3}$ were measured by ECLIA from Roche Diagnostics $\mathrm{GmbH}$, Mannheim, Germany, using commercial Elecsys System 2010. DHEA and its sulfate were determined by RIA, using the kits from Immunotech (Prague Division, Czech Republic). The coefficients of variation for all the assays corresponded to the values declared by manufacturers. $7 \alpha-$ and $7 \beta$-OH-DHEA were measured by RIAs developed in the author's laboratory (Lapčík et al. 1998, 1999).

\section{Statistics}

For evaluation of the differences between the stages of the experiment, repeated measures one-way ANOVA was used with stage as a within-factor. Special care was given to data pretreatment respecting nonGaussian data distribution, heteroscedascity (nonconstant variance) and non-homogeneity. The data were transformed by power transformation to attain minimum skewness of studentized residuals. To eliminate the influence of outliers, only the data with an absolute studentized value less than 2.5 were considered. The ANOVA was completed using statistical software Statgraphics Plus 5 (Manugistics, Rockville, MD, USA).

\section{Results}

Changes of steroid levels before (Day 0, Stage 1), during (Day 5, Stage 2) and after (Days 9, 16 and 72, Stages 3-5) application of 7-oxo-DHEA to 21 male volunteers are shown in Figure 1, the corresponding levels of thyroid parameters can be found in Figure 2. 
7a-OH-DHEA

$[\mathrm{nmol} / \mathrm{L}]$

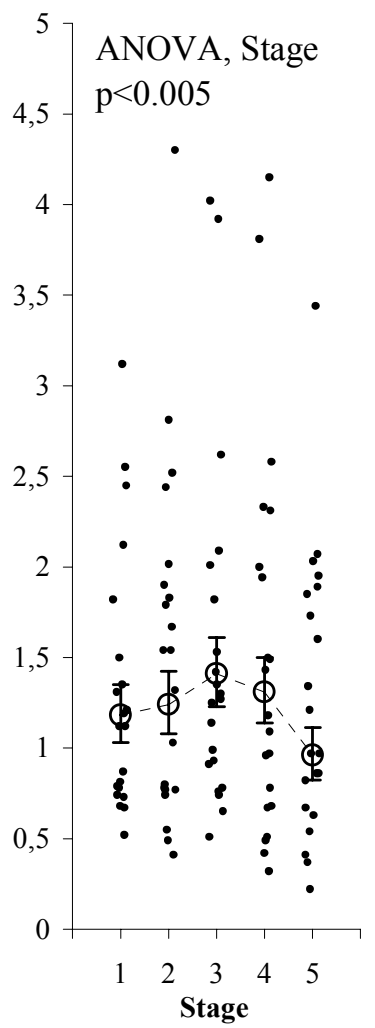

TSH

$[\mathrm{mU} / \mathrm{L}]$

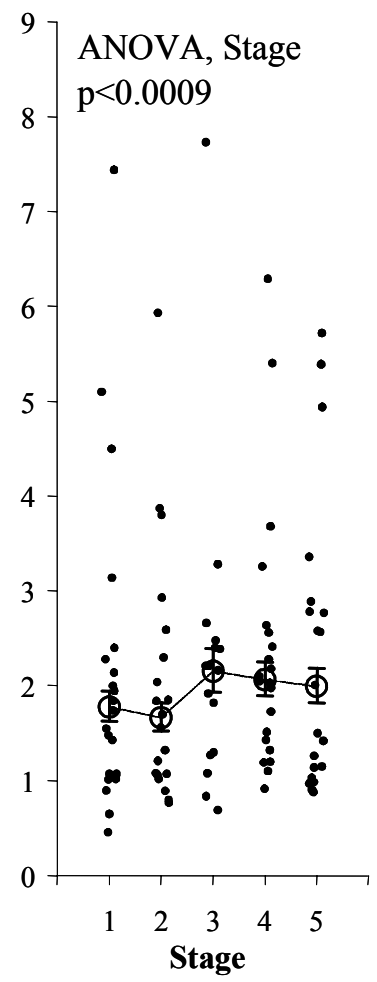

7ß-OH-DHEA

$[\mathrm{nmol} / \mathrm{L}]$

14 ANOVA, Stage

$\mathrm{p}<0.0001$

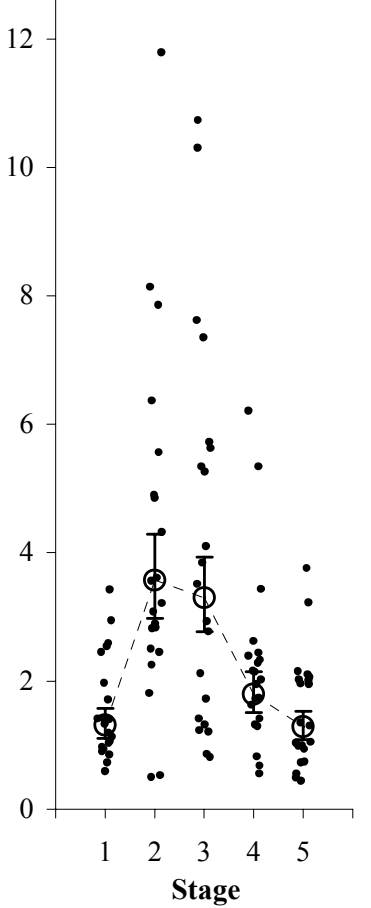

fT4

$[\mathrm{nmol} / \mathrm{L}]$

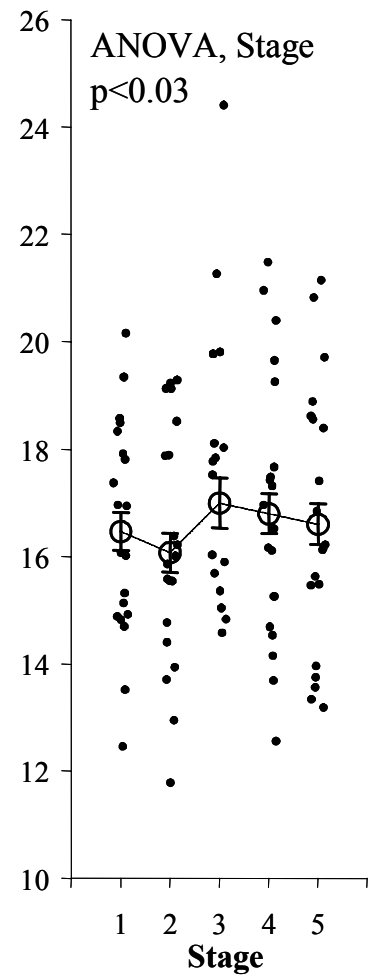

Fig. 1. Changes of serum levels of 7-OH-DHEA epimers before, during, and after transdermal application of 7-oxo-DHEA to 21 healthy males. Repeated measures ANOVA with stage of treatment as the within-factor was used for evaluation of the significance of the changes. Careful data analysis and the residual analysis were performed prior to test, to identify nonGaussian data distribution and heteroscedascity. In the case of skewed data distribution and/or non-constant variance, the original data were transformed to minimum skewness before the analysis. The data with the absolute standardized residuals or absolute standardized values within individual stages greater than 3 were excluded from the computations. To avoid a masking effect of the most pronounced outliers, repeated outlier exclusion was used. Maximum number of excluded experimental points never exceeded $5 \%$ of the total. The small full circles represent experimental points, the big empty circles with error bars represent transformed group means with $95 \%$ confidence intervals after re-transformation to the original scale.
fT3

[nmol/L]

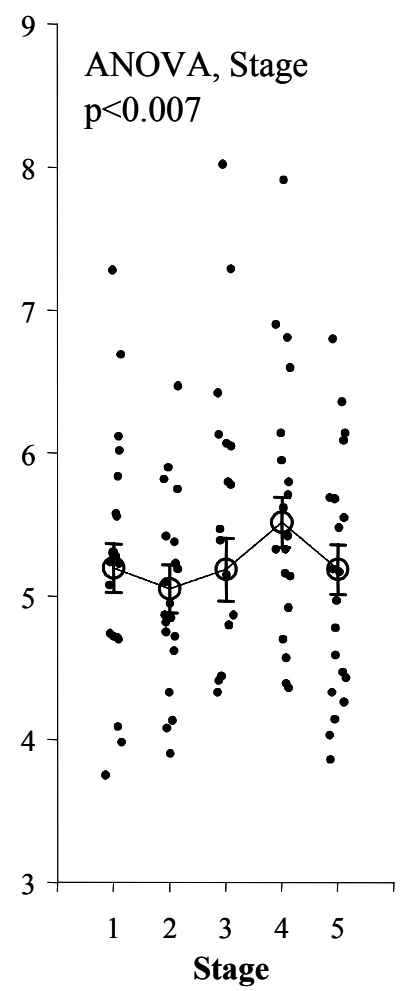

Fig. 2. Changes of serum levels of three major thyroid markers (TSH, fT3 and fT4) before, during, and after transdermal application of 7-oxo-DHEA to 21 healthy males. The statistical analysis was the same as described in the legend of Figure 1. 
Table 1. Spearman's correlation matrix of the relations between DHEA, its 7-hydroxylated metabolites, thyroid markers, and age; basal values. The upper right parts from the diagonal represent simple pair- while the lower left parts the partial correlations. Each cell from above represents coefficient of correlation, significance and number of pairs. The significant correlations are shaded.

\begin{tabular}{|c|c|c|c|c|c|c|c|}
\hline Age & $\begin{array}{c}-0.682 \\
0.001 \\
21\end{array}$ & $\begin{array}{c}-0.588 \\
0.005 \\
21\end{array}$ & $\begin{array}{c}-0.626 \\
0.002 \\
21\end{array}$ & $\begin{array}{c}-0.633 \\
0.002 \\
21\end{array}$ & $\begin{array}{c}-0.406 \\
0.068 \\
21\end{array}$ & $\begin{array}{c}-0.280 \\
0.219 \\
21\end{array}$ & $\begin{array}{c}-0.158 \\
0.495 \\
21\end{array}$ \\
\hline $\begin{array}{c}-0.140 \\
0.618 \\
21 \\
\end{array}$ & DHEA & $\begin{array}{c}0.704 \\
0.000 \\
21 \\
\end{array}$ & $\begin{array}{c}0.600 \\
0.004 \\
21 \\
\end{array}$ & $\begin{array}{c}0.653 \\
0.001 \\
21 \\
\end{array}$ & $\begin{array}{c}0.424 \\
0.056 \\
21 \\
\end{array}$ & $\begin{array}{c}0.222 \\
0.333 \\
21 \\
\end{array}$ & $\begin{array}{c}-0.014 \\
0.953 \\
21 \\
\end{array}$ \\
\hline $\begin{array}{c}-0.280 \\
0.312 \\
21 \\
\end{array}$ & $\begin{array}{c}0.456 \\
0.088 \\
21 \\
\end{array}$ & DHEAS & $\begin{array}{c}0.381 \\
0.089 \\
21 \\
\end{array}$ & $\begin{array}{c}0.567 \\
0.007 \\
21 \\
\end{array}$ & $\begin{array}{c}0.305 \\
0.179 \\
21 \\
\end{array}$ & $\begin{array}{c}0.545 \\
0.011 \\
21 \\
\end{array}$ & $\begin{array}{c}0.196 \\
0.396 \\
21 \\
\end{array}$ \\
\hline $\begin{array}{c}-0.384 \\
0.158 \\
21 \\
\end{array}$ & $\begin{array}{c}0.198 \\
0.480 \\
21 \\
\end{array}$ & $\begin{array}{c}-0.428 \\
0.112 \\
21\end{array}$ & DHEA $7 \alpha$ & $\begin{array}{c}0.712 \\
0.000 \\
21 \\
\end{array}$ & $\begin{array}{c}0.260 \\
0.255 \\
21 \\
\end{array}$ & $\begin{array}{c}0.207 \\
0.367 \\
21 \\
\end{array}$ & $\begin{array}{c}0.072 \\
0.755 \\
21 \\
\end{array}$ \\
\hline $\begin{array}{c}0.087 \\
0.759 \\
21\end{array}$ & $\begin{array}{c}0.069 \\
0.807 \\
21\end{array}$ & $\begin{array}{c}0.406 \\
0.133 \\
21\end{array}$ & $\begin{array}{c}0.703 \\
0.003 \\
21\end{array}$ & DHEA7 $\beta$ & $\begin{array}{c}0.208 \\
0.366 \\
21\end{array}$ & $\begin{array}{c}0.147 \\
0.524 \\
21\end{array}$ & $\begin{array}{c}0.138 \\
0.552 \\
21\end{array}$ \\
\hline $\begin{array}{c}-0.235 \\
0.398 \\
21 \\
\end{array}$ & $\begin{array}{c}0.099 \\
0.726 \\
21 \\
\end{array}$ & $\begin{array}{c}0.211 \\
0.450 \\
21 \\
\end{array}$ & $\begin{array}{c}0.129 \\
0.646 \\
21 \\
\end{array}$ & $\begin{array}{c}-0.213 \\
0.447 \\
21 \\
\end{array}$ & TSH & $\begin{array}{c}-0.152 \\
0.511 \\
21 \\
\end{array}$ & $\begin{array}{c}-0.209 \\
0.363 \\
21 \\
\end{array}$ \\
\hline $\begin{array}{c}0.050 \\
0.858 \\
21 \\
\end{array}$ & $\begin{array}{c}-0.245 \\
0.379 \\
21\end{array}$ & $\begin{array}{c}0.651 \\
0.009 \\
21 \\
\end{array}$ & $\begin{array}{c}0.375 \\
0.168 \\
21 \\
\end{array}$ & $\begin{array}{c}-0.374 \\
0.170 \\
21 \\
\end{array}$ & $\begin{array}{c}-0.304 \\
0.270 \\
21 \\
\end{array}$ & FT4 & $\begin{array}{c}0.409 \\
0.065 \\
21 \\
\end{array}$ \\
\hline $\begin{array}{c}-0.156 \\
0.578 \\
21 \\
\end{array}$ & $\begin{array}{c}-0.087 \\
0.759 \\
21 \\
\end{array}$ & $\begin{array}{c}-0.065 \\
0.817 \\
21 \\
\end{array}$ & $\begin{array}{c}-0.132 \\
0.639 \\
21 \\
\end{array}$ & $\begin{array}{c}0.201 \\
0.472 \\
21 \\
\end{array}$ & $\begin{array}{c}-0.098 \\
0.729 \\
21 \\
\end{array}$ & $\begin{array}{c}0.274 \\
0.324 \\
21 \\
\end{array}$ & FT3 \\
\hline
\end{tabular}

Table 2. Spearman's correlation matrix of the relations between DHEA, its 7-hydroxylated metabolites, thyroid markers, and age; all the data obtained during and after treatment. The upper right parts from the diagonal represent simple pair- while the lower left parts the partial correlations. Each cell from above represents coefficient of correlation, significance, and number of pairs. The significant correlations are shaded.

\begin{tabular}{|c|c|c|c|c|c|c|c|}
\hline Age & $\begin{array}{c}-0.663 \\
0.000 \\
84\end{array}$ & $\begin{array}{c}-0.593 \\
0.000 \\
84 \\
\end{array}$ & $\begin{array}{c}-0.453 \\
0.000 \\
84 \\
\end{array}$ & $\begin{array}{c}-0.139 \\
0.206 \\
84 \\
\end{array}$ & $\begin{array}{c}-0.403 \\
0.000 \\
77 \\
\end{array}$ & $\begin{array}{c}-0.254 \\
0.027 \\
76 \\
\end{array}$ & $\begin{array}{c}-0.118 \\
0.312 \\
76 \\
\end{array}$ \\
\hline-0.277 & & 0.703 & 0.378 & 0.021 & 0.274 & 0.267 & 0.197 \\
\hline 0.014 & DHEA & 0.000 & 0.000 & 0.847 & 0.016 & 0.020 & 0.088 \\
\hline 84 & & 84 & 84 & 84 & 77 & 76 & 76 \\
\hline-0.273 & 0.522 & & 0.347 & 0.076 & 0.069 & 0.380 & 0.132 \\
\hline 0.016 & 0.000 & DHEAS & 0.001 & 0.494 & 0.553 & 0.001 & 0.257 \\
\hline 84 & 84 & & 84 & 84 & 77 & 76 & 76 \\
\hline-0.262 & 0.168 & -0.026 & & 0.488 & 0.035 & 0.230 & 0.034 \\
\hline 0.020 & 0.139 & 0.817 & DHEA $7 \alpha$ & 0.000 & 0.761 & 0.045 & 0.768 \\
\hline 84 & 84 & 84 & & 84 & 77 & 76 & 76 \\
\hline-0.025 & -0.153 & 0.009 & 0.477 & & -0.035 & 0.122 & 0.048 \\
\hline 0.828 & 0.179 & 0.938 & 0.000 & DHEA $7 \beta$ & 0.762 & 0.296 & 0.678 \\
\hline 84 & 84 & 84 & 84 & & 77 & 76 & 76 \\
\hline-0.424 & 0.158 & -0.234 & -0.159 & 0.005 & & -0.085 & -0.125 \\
\hline 0.000 & 0.186 & 0.047 & 0.175 & 0.969 & TSH & 0.468 & 0.284 \\
\hline 77 & 77 & 77 & 77 & 77 & & 76 & 76 \\
\hline-0.041 & -0.061 & 0.247 & 0.101 & 0.024 & -0.062 & & 0.435 \\
\hline 0.735 & 0.614 & 0.037 & 0.393 & 0.838 & 0.600 & FT4 & 0.000 \\
\hline 76 & 76 & 76 & 76 & 76 & 76 & & 76 \\
\hline-0.078 & 0.169 & -0.147 & -0.143 & 0.065 & -0.164 & 0.403 & \\
\hline 0.523 & 0.159 & 0.219 & 0.228 & 0.585 & 0.160 & 0.000 & FT3 \\
\hline 76 & 76 & 76 & 76 & 76 & 76 & 76 & \\
\hline
\end{tabular}


Both 7-OH-DHEA isomers were increased by the treatment, and the between-stage differences revealed by ANOVA were highly significant. Maximum values of $7 \beta$-OH-DHEA were reached as early as during treatment (Stage 2), while those of $7 \alpha-\mathrm{OH}-\mathrm{DHEA}$ immediately after finishing the treatment (Stage 3). The rise of $7 \beta-\mathrm{OH}-\mathrm{DHEA}$ was much more pronounced, being almost three times higher than the basal level. No significant changes were observed in DHEA/S levels.

As TSH and free thyroid hormones are concerned, in all instances the same trend was observed, namely a slight decrease of the levels during treatment (Day 5), followed by a small but significant rise, and then return again to the basal levels. An increase of TSH was not accompanied by opposite changes in thyroid hormone levels.

The basal data as well as those obtained at different stages of treatment (including those after termination of the administration) were mutually correlated. With respect to age differences of men, age was included as an additional parameter. Table 1 shows the correlation matrix for basal values, while Table 2 shows the correlation matrix for all the data obtained during and after treatment. The upper right parts from the diagonal represent simple paired values while the lower left parts the partial correlations. Correlation analysis was also performed separately for all stages of treatment (data not given), but they did not differ from those shown in Table 2.

\section{Discussion}

Early rise of $7 \beta-\mathrm{OH}-\mathrm{DHEA}$ to values almost three times higher than those of $7 \alpha-\mathrm{OH}$-epimer during and after 7-oxo-DHEA application is in agreement with finding that the former is the prevailing reduced 7-oxoDHEA metabolite (Robinzon et al. 2003). The fact that at least the levels of $7 \beta-\mathrm{OH}-\mathrm{DHEA}$ still remained significantly increased one week after termination of 7-oxo-application may be considered advantageous with respect to its potentially beneficial effect.

The aim of correlation analysis was to reveal possible relations between DHEA/S and its 7-hydroxylated metabolites on one hand, and thyroid parameters on the another. Considering the basal levels, the only positive correlation found by both statistical approaches was between DHEAS and $\mathrm{fT}_{4}$. This is in agreement with higher DHEA/S levels in hyperthyroidism and lower levels in hypothyroidism reported by Tagawa et al. (2000). When all the data during and after treatment were put together irrespective of the stage, the positive correlation was extended to unconjugated DHEA. There was, however, no relationship between any thyroid parameter and 7-OH-DHEA epimers, with only marginal positive correlation between $7 \alpha-\mathrm{OH}-\mathrm{DHEA}$ and $\mathrm{fT}_{4}$ found by a simple pair method. In keeping with previous reports (Hampl et al. 2001), a significant decline of DHEA/S and its 7-hydroxylated metabolites was observed with age.

It was concluded that short-term treatment with 7-oxo-DHEA does not significantly affect the thyroid parameters, and that it provides considerable amounts of $7 \beta$-hydroxy-DHEA.

\section{Acknowledgements}

The study was supported by the Grant No 7815-3 from the Internal Grant Agency of the Czech Ministry of Health.

\section{References}

BOBYLEVA V, BELLEI M, KNEER N, LARDY H: The effects of ergosteroid 7-oxo-dehydroepiandrosterone on mitochondrial membrane potential: possible relationship to thermogenesis. Arch Biochem Biophys 341: 122 128, 1997.

HAMPL R, LAPČÍK O, HILL M, KLAK J, KASAL A, NOVÁČEK A, ŠTERZL I, ŠTERZL J, STÁRKA L: 7-Hydroxydehydroepiandrosterone - a natural antiglucocorticoid and a candidate for steroid replacement therapy. Physiol. Res 49 (Suppl.1): S107-S112, 2000.

HAMPL R, HILL M, STÁRKA L: 7-Hydroxydehydroepiandrosterone epimers in the life span. J Steroid Biochem Mol Biol 78: 367-372, 2001.

HAMPL R, HILL M, BÍLEK R, STÁRKA L: Relation of dehydroepiandrosterone and its 7-hydroxylated metabolites to thyroid parameters and sex hormone-binding globulin (SHBG) in healthy subjects. Clin Chem Lab Med 41: 1081-1086, 2003.

IHLER G, CHAMI-STEMMAN H: 7-Oxo-DHEA and Raynaud's phenomenon. Med Hypotheses 60: 391-397, 2003. 
KALIMI M, REGELSON W (eds): Dehydroepiandrosterone (DHEA), Biochemical, Physiological and Clinical Aspects. W de Gruyter, Berlin, 2000.

KALIMI M, SHAFAGOJ Y, LORIA RM, PADGETT D, REGELSON W: Anti glucocorticoid effects of dehydroepiandrosterone (DHEA). Mol Cell Biochem 131: 99-104, 1994.

LAPČÍK O, HAMPL R, HILL M, BIČÍKOVÁ M, STÁRKA L: Immunoassay of 7-hydroxysteroids: 1. Radioimmunoassay of 7ß-hydroxy-dehydroepiandrosterone. J Steroid Biochem Mol Biol 67: 439-445, 1998.

LAPČÍK O, HAMPL R, HILL M, STÁRKA L: Immunoassay of 7-hydroxysteroids: 2. Radioimmunoassay of $7 \alpha-$ hydroxy-dehydroepiandrosterone. J Steroid Biochem Mol Biol 71: 231-237, 1999.

MARWAH A, MARWAH P, LARDY H: Development and validation of a high-performance liquid chromatography assay for the quantitative determination of 7-oxo-dehydroepiandrosterone-3 $\beta$-sulfate in human plasma. J Chromatogr B 721: 197-205, 1999.

MORFIN R: Involvement of steroids and cytochromes $\mathrm{P}_{450}$ species in the triggering of immune defense (Review). J Steroid Biochem Mol Biol 80: 273-290, 2002.

ROBINZON B, MICHAEL KK, RIPP SL, WINTERS SJ, PROUGH RA: Glucocorticoids inhibit interconversion of 7hydroxy and 7-oxo metabolites of dehydroepiandrosterone: a role for $11 \beta$-hydroxysteroid dehydrogenases? Arch Biochem Biophys 412: 251-258, 2003.

ŠULCOVÁ J, ŠTULC T, HILL M, HAMPL R, MAŠEK Z, VONDRA K, ČEŠKA R: Decrease in serum dehydroepiandrosterone level after fenofibrate treatment in males with hyperlipidemia. Physiol Res 54: 151$157,2005$.

TAGAWA N, TAMANAKA J, FUJINAMI A, KOBAYASHI Y, TAKANO T, FUKATA S, KUMA K, TADA H, AMINO N: Serum dehydroepiandrosterone, dehydroepiandrosteronesulfate, and pregnenolone sulfate concentrations in patients with hyperthyroidism and hypothyroidism. Clin Chem 46: 523-528, 2000.

TAGAWA N, TAKANO T, FUKATA S: Serum concentrations of androstenediol and androstenediol sulfate in patients with hyperthyroidism and hypothyroidism. Endocr J 48: 345-54, 2001.

\section{Reprint requests}

Richard Hampl, Institute of Endocrinology, Národní 8, 11694 Praha 1, Czech Republic. E-mail: rhampl@endo.cz 